\title{
Reflections on the Necessity of Constructing a New Energy Vehicles Major
}

\author{
Shanshan Guo ${ }^{1, a^{*}}$, Yun Liu ${ }^{1}$, Gang Wang ${ }^{2}$ and Jinpeng Tian ${ }^{3}$ \\ ${ }^{1}$ School of Mechanical and Vehicle Engineering, Weifang University 261061 \\ ${ }^{2}$ School of Automobile Engeering, Shandong Jiaotong University 250023 \\ ${ }^{3}$ School of Mechanical Engineering, Beijing Institute of Technology 10081 \\ alucy001478@163.com \\ *The corresponding author
}

Keywords: New energy vehicle major; Major settings; Necessity

\begin{abstract}
The Government attaches great importance to the new energy automotive industry, so the new energy automotive industry develops rapidly. Meanwhile, the demands of the new energy vehicles professionals become more and more urgent. However, as the new energy vehicles industry is a new subject emerging relatively late and involving a wide range of fields, so in China, few colleges and universities have set up new energy vehicle major. In this paper, on the basis of discussing relevant national policies, the status of new energy vehicle major and the urgent need of major talents are analyzed, and the necessity and significance of setting up new energy vehicle major are discussed.
\end{abstract}

\section{Introduction}

At present, under strategy-oriented of the sustainable development, China develops the green and ecological economy vigorously, and implements energy-saving emission reduction policies. One of the important initiatives to reduce oil consumption and carbon dioxide emissions is the development of new energy vehicles. The clear objective is: By 2020, Pure electric vehicles and plug-in hybrid vehicle production capacity of 2 million, the cumulative production and marketing more than 5 million. By 2025, China's new energy vehicles in the automotive market will reach annual sales volume of $20 \%$, Autonomous new energy vehicle market account for more than $80 \%$ [1]. With the development of new energy vehicles, production and sale of new energy vehicles of China grows largely since 2014(Fig1.), meantime the demand for talents rises continuously [2]. In future, the need of professionals familiar with the structure of new energy vehicles, principles, research and development and fault detection and maintenance professionals is urgent. The primary task is accelerating the cultivation of new energy vehicle professionals to promote the development of new energy vehicles. 


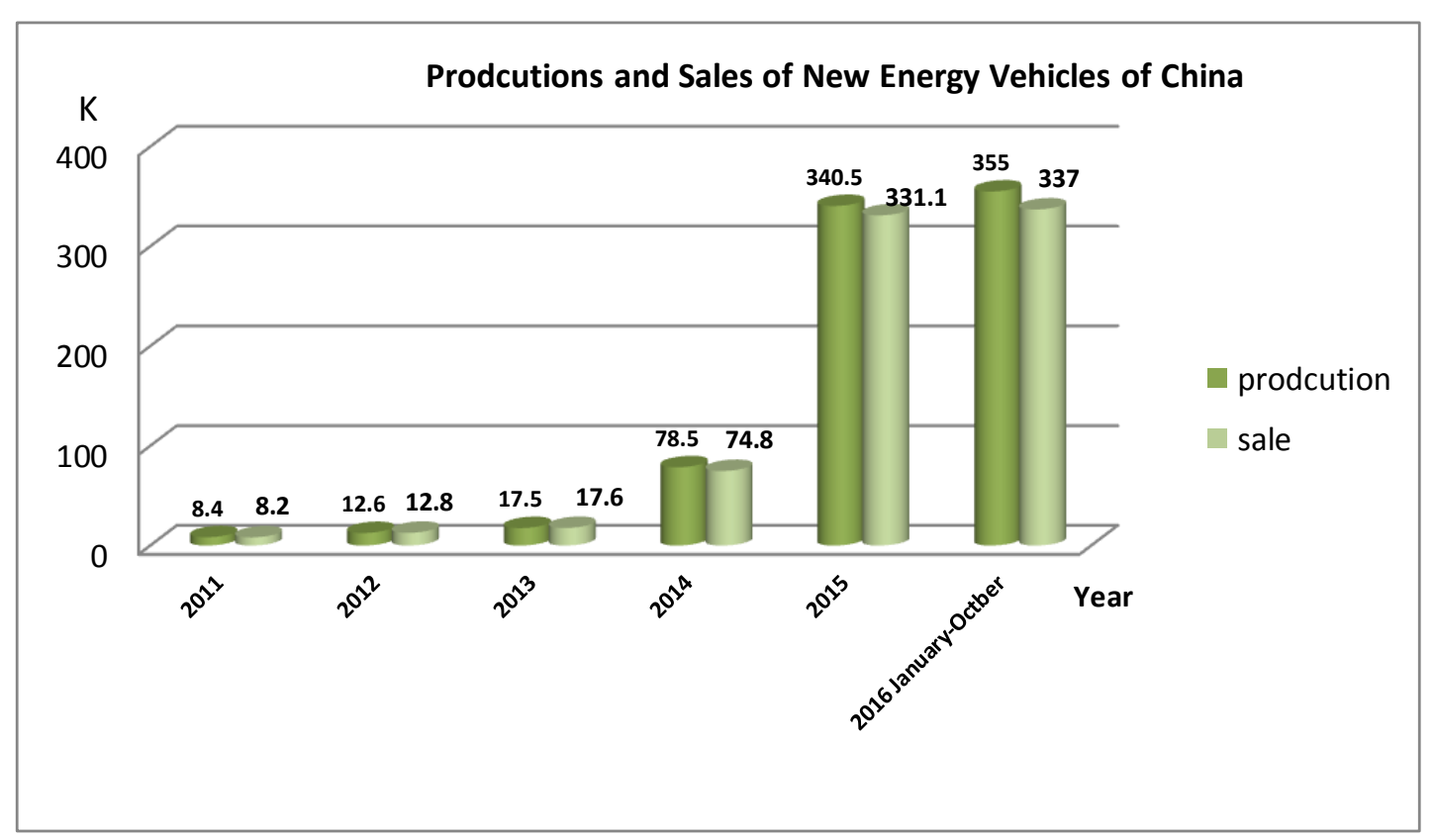

Figure 1. Productions and Sales of New Energy Vehicles of China

\section{Current Status of Domestic New Energy Vehicles Major}

Currently, Major domestic institutions, such as Tsinghua University, Tongji University, Jilin University, Beijing Institute of Technology, Southwest Jiaotong University, Hunan University have opened the new energy vehicle major or direction[3].

In general, the scale of the professional institutions is still relatively little. And other institutions do not have the ability to open new energy major or train a large number of new energy graduates at least three to five years later. However, even after three years, colleges and universities have the ability to train High - level graduates, they also have to go through at least four years of undergraduate study. That is to say, new energy companies can fully alleviate the problem of lack of talent at least seven years later. A huge talent scarcity led to the vicious competition among companies. The difficulty of recruitment becomes the biggest bottleneck restricting the development of enterprises. For manufacturing companies, as new energy industry relates to high-tech issues, the need for professional high-tech graduates is eager, while the domestic training talent demand is far behind.

Secondly, although the new energy vehicles have good prospects for development, there are still many industry limitations, including the production limitations, maintenance and testing limitations of new energy vehicles. So it is difficult to provide practical operating conditions for students [4].

In addition, the constriction of these institutions' own conditions and their lack of professional teachers also lead to inability to start the personnel training mechanism. Further on, they cannot guarantee the quality of new energy vehicle talent training [5].

\section{Quality Demands of New Energy Vehicles Major}

New energy automotive industry consists of two parts: one is the new energy automotive manufacturing industry, the other is the new energy automotive applications market. Therefore, the work scope of new energy vehicles major is mainly the manufacture of new energy vehicles, new energy vehicle testing, maintenance and others [6]. Because the structure and technology of new energy vehicles and traditional cars are very different, the technical requirements are also not the same. At present, students major in the new energy vehicles need to have the following qualities [7]: 
Firstly, new energy automotive professionals should have much electronic knowledge, to understand the advanced energy-saving materials, at the same time they have to master certain information technology. And new energy vehicles also involve a number of battery management and other power-driven devices, as well as some power control and intelligent technology. Therefore, automotive professionals should master this knowledge, to work effectively.

Secondly, during the use process, whether the traditional cars or new energy vehicles, there will be some troubles. Therefore, car maintenance is necessary. For the new energy vehicle maintenance professionals and technicians, they not only need to master the traditional vehicle maintenance technology, but also should have the qualification certificates of new energy vehicles. According to the needs of new energy vehicles, compared with traditional cars, the new energy vehicle maintenance staffs are required higher professional skills, so they must master rich theoretical knowledge and have good practical abilities.

Thirdly, new energy vehicles are very different in the structural design and power principle, so the operating ways have also undergone major changes. At present, new energy vehicles cover many new technologies, it also leads to high technical requirements to new energy vehicles major.

Therefore, the creation of the new energy vehicle major, not only improves the technical level of students after graduation and abilities to sustainable development, but also keeps up with the new energy vehicles technology development.

\section{The Necessity of Opening a New Energy Vehicles Major}

\section{The Strategic Necessity of Setting up New Energy Vehicle Major}

Implement of new energy vehicles can greatly solve the energy crisis, environmental pollution problems, rapidly promote development of the automobile manufacturing industry, parts, raw materials and other enterprises. New Energy Vehicle is the core technology to enhance the national competitiveness, promote economic development and social progress. Although "Made in China" is advocated,it do still not have a core technology, big but not strong. At present, there is still a wide gap in the automotive technology level among China and the world's advanced countries, so it is urgent to train a large number of well-educated vehicle engineering professionals.

\section{The Significance of Opening a New Energy Automobile Specialty to the Automobile Industry}

Because China's auto industry started too late, although it has its own research team, it is still short of car talents. The automotive industry $\mathrm{R}$ and D personnel in Europe and the United States and other developed countries generally accounted for more than $30 \%$, while our proportion is less than $8 \%$. Compared with the rapid development of the automobile industry, China's auto industry demand for talent status appears disproportionate [6]. In the next five years, the needs of high-level specialized personnel are large in the automotive industry of new energy vehicles, digital and intelligent manufacturing, automotive electronics technology. Therefore, the creation of new energy vehicles major can train a large number of high-tech professionals for the new energy vehicle manufacturing, new energy vehicle testing, maintenance and other fields. It can also meet the automotive industry's demand for new energy vehicles talents.

\section{The significance of setting new energy vehicles major to service local economic}

For example, in Weifang city, many enterprises are currently related to vehicle engineering major of Weifang university. The automotive industry covers the vehicle manufacturing, engine, chassis, automotive electronics and other parts manufacturing and other fields. There are a large number of new energy vehicles and spare parts manufacturing enterprises such as Weichai Power, Ruichi, Kaima cars, BYVIN electric vehicles. Weifang Diesel is now leading the formation of new energy vehicles and parts manufacturing. BYVIN is the representative of low-speed new energy vehicles as a multi-field industrial clusters, and it needs to recruit about 1,000 graduates each year. At present, each year, students graduate from vehicle engineering, machinery manufacturing and automation, industrial design and other majors in Weifang university are about 350, accounts for $30 \%$ of the demand for graduates. Job vacancy is huge. In order to enhance the technical level, master the core technology, about 500 graduate students are hired as the members of core research 
and development team, but there are still blank in Weifang university, less than 300 graduates in Shandong province per year. Therefore, the construction of new energy vehicles major can train local enterprises and transport qualified technical personnel, and play a social and radiological demonstration of the region.

\section{Conclusion}

To sum up, the state vigorously develops new energy vehicles, which is the inevitable development trend of the automotive industry, the construction of new energy vehicles major is already a social and industry development need. Therefore, in the new car development situation, the major institutions of higher learning should actively respond to national policies, to meet the needs of industry development, reform of their professional orientation. if conditions permitting, new energy vehicles major should be set up. Combined with industry and society needs, personnel training objectives and personnel training mode should be planned, new teaching materials should be prepared, a new curriculum system should be constructed. Through recruitment or retraining existing teachers and other means, the teaching level of teachers is enhanced, and the school-enterprise cooperation model should be deepened. In these ways, the cultivation of new energy automotive professionals can meet the needs of social positions, train more high-quality talents for our country.

\section{Acknowledgment}

This work was supported by the Shandong province natural science foundation (ZR2015EL024) And Weifang City Science and Technology Development Project2016GX012

\section{References}

[1] National Medium and Long-term Education Reform and Development Plan (2010-2020).

[2] http://www.evpartner.com/news/11/detail-24148.html.

[3] http://hf.xdf.cn/201512/288247744.html.

[4] SHEN Cai-ying, DUAN Min, TANG Yang-shan. Research on Construction of New Energy Automobile Engineering Practice Education [J]. Journal of Liaoning University of Technology: Social Sciences Edition, 2014(3):126-127.

[5] Huang Xiongjian. Research on the Innovative Talents Cultivation Model of Applicationoriented Automobile [J]. Science and Technology Review, 2010 (29):163-164.

[6] CHAN Lv. Research and Practice on Talents Training Mode of Applied Automobile Specialty [J]. Equipment Manufacturing Technology, 2013 (2):112-136.

[7] YU Zhengxin. Reflections on Personnel Training in the Context of Strategic Emerging Industries [J]. Science and technology to get rich guide, 2011 (23):319. 